\title{
TOMÁS TAMAYO DE VARGAS YAUGUSTA EMERITA: COROGRAFÍA, HAGIOGRAFÍA Y LA RECUPERACIÓN DEL PASADO ROMANO
}

\author{
Jorge Tomás García*
}

\begin{abstract}
Of the many Antiquities that were used to illustrate the Utopia of the Golden Age in the seventeenth century, one of the most recurrent was that of Augusta Emerita. This process of literary recovery allows us to affirm that there were "emeritenses rebirths". Tomás Tamayo de Vargas (1589-1641) bequeathed us one of the most valuable testimonies for the reconstruction of Augusta Emerita. Within the hagiographic fashion of his time, the Vitas Sanctorum Patrum Emeretensium was reissued. In his version, Tamayo de Vargas includes an appendix entitled Apospasmation. The purpose of the work is to gather testimony to document as accurately as possible its vision of the emeritense past. In this article, we present a critical study of the Latin work of Tamayo de Vargas, in addition to trying to define the cultural context in which the need to recover the Roman past of Mérida is generated.
\end{abstract}

Keywords: Augusta Emerita, Tomás Tamayo, hagiography, corography, Conde de la Roca.

Palabras clave: Augusta Emerita, Tomás Tamayo, hagiografía, corografía, Conde de la Roca.

\footnotetext{
* Universidad Autónoma de Madrid, Departamento de Historia y Teoría del Arte, c/ Francisco Tomás y Valiente, 28049 Madrid. Este trabajo se encuadra en el contexto del "Grupo de Investigación de Excelencia Estudios Visuales” (Fundación Séneca, 19905/GERM/15).
} 


\section{1. \\ Tomás Tamayo de Vargas como cronista real}

Tomás Tamayo de Vargas es una de las figuras capitales para conocer las tendencias literarias y culturales del primer tercio del siglo XVII en España. No existe unanimidad sobre la fecha de su nacimiento, ya que pudo ser en Madrid a finales de 1588, o en los primeros días de 1589 (González Hernández, 2012: 22). Con tan solo veinte años defendió al historiador Juan Mariana en su Defensa de la Historia General de España del Padre Juan de Mariana (Toledo, 1616). A la misma edad presentó solicitud para el cargo de cronista real pero no fue elegido, pasando el oficio a manos de Francisco de Rioja, que contó con el apoyo del conde de Olivares (Túrrez, 2008: 794). En 1621 el rey le nombró secretario de Fernando Álvarez de Toledo, por aquel entonces embajador de España en Venecia (Ginarte González, 1989: 735). A su regreso a España (1625) fue maestro del cardenal Enrique de Guzmán y Haro, sobrino del Conde Duque de Olivares. Fue también -con el consentimiento de Felipe IV- preceptor del hijo mayor del conde de Melgar, Juan Enríquez de Cabrera. Poco después, Felipe IV le concedió el cargo de Cronista General de Castilla, al fallecer Antonio de Herrera, y después sucedió a Luis Tribaldos de Toledo como Cronista de Indias (Cuesta Domingo, 2007: 133-135). Finalmente, consiguió una plaza de ministro en el Real Consejo de las Órdenes Militares y otra en el Consejo de la Santa Inquisición en 1637, empleos que disfrutó muy poco tiempo, pues falleció en septiembre de 1641 en Madrid.

Esta notable biografía de méritos políticos permitió a Tamayo tener acceso a las principales fuentes de información y archivos históricos de la época en Madrid o Sevilla, estando relacionado con los círculos de poder más cercanos a Felipe IV. Gracias a este fecundo bagaje fue uno de los escritores más prolíficos de su siglo. Dedicó gran parte de sus obras a temas históricos, descripciones, antigüedades, elogios de los reinos, de las ciudades o historias locales (García Murga Alcántara, 
2001: 190)1. Menéndez Pelayo en su Bibliografía hispano-latina clásica, destaca su labor como traductor, "perito latinista", más que como poeta, al referirse a la traducción de la Epistola a los Pisones del Arte Poética de Horacio (Alemán Illán, 1997: 119)². De entre sus obras ha pasado a la posteridad como una de las más notables en su tiempo La mayor junta de libros que España ha visto en la lengua castellana hasta el año $1624^{3}$, herramienta fundamental para demostrar la profundidad de la producción intelectual hispana (Ruiz Pérez, 2007: 518; González Hernández, 2012). En Madrid las exigencias políticas no sólo determinaban el tipo de historia que se escribía, sino también la creación de dinámicas agencias de publicidad capaces de producir historias por encargo. Los cronistas se percataron de que debían contar con instrumentos útiles de trabajo para escribir sus obras y tratar de ganarse la opinión favorable de los políticos de entonces (García Hernán, 2006: 135; Kagan, 2010: 284-285).

Gracias a su capacidad para mantenerse independiente del tipo de historia política que había encargado escribir a la Junta de Cronistas (Sierra Matute, 2009: 140), Tamayo pudo dedicar tiempo y esfuerzo a escribir "otras historias": entre ellas, la que nos interesa en el presente trabajo, la recopilación que hizo de las antigüedades de Augusta Emerita en su Apospasmation de rebus emeritensibus (Amberes, 1638). De esta manera, podemos afirmar que esta independencia le permitió dedicarse a otras empresas literarias "menores" como el Apospasmation.

1 A modo de ejemplo se citan: Memorial por la perpetua lealtad de la ciudad de Toledo, Apospasmation de rebus Emeritensibus, Toletum, sive de rebus toletanis historia. Llevó a cabo traducciones como La Constancia de Justo Lipsio, y las Obras de Marcial.

2 Sin duda, la faceta de la personalidad literaria de Tamayo de Vargas que menos se conoce es la de traductor. A ello contribuye, naturalmente, el hecho de que algunas de sus traducciones nunca vieran la imprenta.

3 Olivares solo solicita una vez los servicios de Tamayo, cuando le pidió escribir una crónica de la recuperación de Bahía: Restauración de la ciudad del Salvador Baia de todos sanctos en la provincia del Brasil (1626). 


\section{Hagiografía, corografía y Augusta Emerita}

De toda esta fructífera actividad creativa, la vertiente que nos interesa de Tamayo es la de escritor de historias locales o "corografías" (Kagan, 2009). Este género histórico tenía como finalidad principal describir en detalle un lugar particular; esto es, una "historia particular". Así, el término diferenciaba claramente la historia de un lugar de una historia "general", restringida éstas a obras como la Historia General de España (1601) de Juan de Mariana. Tamayo fue uno de los principales representantes de este género, y su primera obra que puede ser definida como tal fue la Defensa de Flavio Lucio Dextro (1624), lo que supuso el inicio de una nueva oleada de historias locales. Tal y como afirma Kagan (1995: 57), la mayoría de los libros de este género histórico podían ser consultados en la Corte, ya que el índice realizado en 1637 de los libros conservados en la torre alta del Alcázar Real de Madrid indica que el rey coleccionó, por lo menos, un ejemplar de casi todas las historias municipales.

El nuevo enfoque que estas historias locales van a tener de las antigüedades está profundamente marcado por el incremento de las narraciones hagiográficas que, impulsada por la iglesia como modo de fomentar la piedad popular, va a modificar sustancialmente el modo de interpretar el pasado mítico-legendario de algunas localidades. En este contexto, la antigüedad romana va a servir de telón de fondo en la narración de las vidas y milagros de nuevos mártires cristianos (Álvarez Sáenz de Buruaga, 1949: 571). Tamayo en su reedición de la obra Pauli Diaconi emeritensis liber...-que había sido editada unos años antes por Moreno de Vargas (1638)- ejemplifica cómo la antigüedad romana, la hagiografía de los primeros mártires cristianos y los intereses sociales de ciertas familias de noble abolengo pueden configurar un discurso histórico que está modificando la memoria colectiva en el siglo XVII. La obra de Tamayo y la de Moreno de Vargas -Historia de la ciudad de Merida (1633) - comparten la preocupación por subrayar la consolidación de la iglesia cristiana trinitaria en Hispa- 
nia; así como sus manifestaciones materiales, la construcción de edificios religiosos, tanto en el medio urbano como rural, la divulgación del monaquismo y la creación de monasterios en las ciudades de la Hispania de los siglos VI-VII. Moreno de Vargas ofrece una visión del pasado emeritense romano y paleocristiano complaciente y casi idílico -que, como veremos, contrasta con la realidad material de finales del siglo XVI e inicios del siglo XVII-:

En España, en la provincia que los antiguos llamaron Lusitania, en la parte que tuvo nombre de Vettonia, en sitio levantado y eminente, fue fundada la muy noble y antigua ciudad de Mérida, ribera del memorable río Guadiana, que la baña sus hermosos muros por la parte del Mediodía, haciéndola muy vistosa y alegre (Moreno de Vargas, 1992: 31).

En su Historia de la Ciudad de Merida, Moreno de Vargas expone una antología de los datos que se tienen de Mérida hasta 1633, haciendo especial hincapié en las cuestiones que interesan al historiador para dignificar la tradición religiosa, cultural y espiritual de la ciudad (fundación, historia eclesiástica y religiosa). Por este motivo, describe con minuciosidad la ciudad que puede contemplar cada día, que apenas cuenta con mil habitantes, y lo hace sin el tono peyorativo presente en otros autores (Cerrillo Martín de Cáceres, 2009: 45). La descripción que hace Moreno de Vargas de los edificios romanos es bastante superficial y, aunque acude a las fuentes clásicas para establecer paralelos, a menudo son erróneas. En cualquier caso, su principal valor para nosotros es la descripción del estado en que se encuentran los edificios en esta época y de los restos que aparecen en la ciudad. Además del valor como obra general, la obra de Moreno de Vargas tiene el valor añadido de aportar la visión local sobre los restos arqueológicos. Como muy bien afirma Morán Sánchez, "el interés de Moreno de Vargas por dejar patente que Mérida es la Roma de España responde a este deseo de restitutio memoriae que subsiste en la élite de la sociedad emeritense" (2009: 94). 


\section{3. \\ El destinatario del Apospasmation: el linaje de los Vera en Mérida}

Una vez descrito el ambiente histórico y las corrientes literarias imperantes en la época de Tamayo, debemos comenzar el análisis de los factores más capitales del Apospasmation. En su epistola dedicatoria Tamayo dedica la obra a Don Fernando de Vera y Azevedo, obispo de Cuzco, bautizado en Santa María de Mérida el 6 de septiembre de 1582 (Navarro del Castillo, 1963: 605). La importancia de esta figura es máxima a la hora de contextualizar la universalidad del Apospasmation: nos permite trazar el itinerario vital de la obra, desde la pluma real de Tamayo hasta el arzobispado de Cuzco en Perú, deteniéndonos en la Mérida del primer tercio del siglo XVII para entender los motivos de la recuperación del pasado clásico romano de dicha urbe.

Fernando de Vera, por solicitud al rey de su sobrino Juan Antonio de Vera, fue designado arzobispo de Santo Domingo, pasando luego a las sedes de Lima y Cuzco, asumiendo el obispado en agosto de 1630 y murió en 1638 sin salir de Cuzco (Coello de la Rosa, Numhauser, 2012: 24). Conservamos varias noticias sobre la actividad religiosa de Fray Fernando de Vera en Cuzco: por ejemplo, el 20 de enero de 1636 escribió una carta a Felipe III en que daba cuenta de la libertad con que un franciscano hablaba desde el púlpito de la catedral. Se refería al sermón que pronunció el 20 de febrero de 1635, ante un nutrido auditorio compuesto por las más altas autoridades civiles y eclesiásticas de la ciudad (Coello de la Rosa, Numhauser, 2012: 25). Su estancia en Perú coincidió con los tiempos en los que la monarquía necesitaba resolver su crisis económica y fiscal causada por las guerras en Europa. No cabe duda de que Tamayo dedicó la obra a Fernando de Vera por la familiaridad de éste con el Conde de la Roca-Juan Antonio de Vera y Zúñiga - al que había conocido en el círculo sevillano del Conde Duque de Olivares (Marías, 2012: 45).

En el siglo en el que escribe Tamayo, el linaje de los Vera podía presumir de raíces nobiliarias y prestigio nacional. Esta 
familia fue tejiendo una red de contactos reales que facilitaron la fecundidad de su árbol genealógico. Desde Mérida numerosos miembros de la familia establecieron alianzas con los Zúñiga, Tovar o Figueroa. Pero fue, sin duda, Juan Antonio de Vera y Zúñiga (1583-1658) -Conde de la Roca- uno de los miembros de la familia que mejor supo aprovechar estas relaciones privilegiadas que le concedía su estirpe. Entre ellas, y con especial atención a las academias y tertulias literarias celebradas en distintas casas nobiliarias sevillanas, destacó la del conde duque de Olivares, pero también la del duque de Alcalá, con la que el privado rivalizó por conseguir una de las mejores bibliotecas privadas de España. Su sobrino fue nuestro citado Femando de Vera, obispo de Cuzco, protagonista de la dedicatoria del Apospasmation: gracias a la relación de Tamayo con el círculo cultural del Conde de la Roca podemos afirmar que pudo gestarse la redacción y dedicatoria de la obra. La familia de los Vera estuvo fuertemente sensibilizada con las necesidades materiales y espirituales de Mérida desde finales del siglo XVI. En la época de redacción del Apospasmation Mérida sufrió una grave crisis social, económica y humana (Rodríguez Grajera, 1985). En el XVII, época de mayor auge en la actividad de comunidades religiosas, llegará a tener cuatro conventos de monjas: Santa Olalla, las de la Concepción, el monasterio de Santa María de Jesús - fundado por las monjas franciscanas de la Orden de Santa Clara (las obras comienzan en 1622 y se terminan en 1639) - y las de Montepiedad (regla de San Francisco). Las afecciones de 1620 derivadas de la crisis agrícola de 1629-1631, y el presumible brote de tifus que se produce en los primeros meses de 1659, fueron algunos de los hechos más dramáticos que sumieron a la ciudad en un momento histórico de gran necesidad material. Como muy bien describe Álvarez Sáenz de Buruaga (1994: 29), Fray Fernando de Vera -siendo ya Arzobispo de Cuzco-asignó a la parroquia de Santa María de Mérida un cáliz de oro, patena y corporales, que se guardaban en casas particulares y únicamente tenían uso en las fiestas importantes en que se entregaban al párroco (marzo de 1643). La de Santa Eulalia estrenó campana (Tejada Vizuete, 1998-1999: 134), fabricada por Francisco de la Sota (1639). 
De la Parroquia de Santa María de Mérida apenas quedan testimonios materiales de la que fuera iglesia catedral de Mérida (Vives Castell, 1949: 67), pero conocemos numerosas referencias de carácter literario gracias al escrito anónimo coetáneo titulado Vitas Sanctorum Patrum Emeretensium. Pese a que la Orden de Santiago se reunía en la iglesia de Santa Eulalia, el templo más importante a fines del siglo XV era la iglesia de Santa María (Álvarez Sáenz de Buruaga, 1976: 141). La iglesia principal en tiempos visigodos se llamaba ya también de Santa María, siendo denominada en los textos como "ecclesia senior y sancta Iherusalem". Se acepta generalmente que estuvo localizada en el mismo solar en que hoy se encuentra la iglesia gótica de Santa María en Mérida -en la actual Plaza de España-. Así lo afirma Bernabé Moreno de Vargas, quien dice en 1633 que "en la puerta del Perdón, desde la pila del agua bendita, sube un arco y moldura que es obra conocida de godos" (Moreno de Vargas, 1992: 139). Durante el siglo XVI se amplió el espacio de la iglesia con algunas capillas más: la primera de ellas parece ser la de la familia de los Vera, quizás del primer tercio de este siglo. Está situada en el espacio más noble, en el costado meridional del presbiterio, mostrando exteriormente a la plaza dos blasones de la familia, realizados en mármol blanco, en la culminación de los contrafuertes angulares. La Capilla del Conde de la Roca está situada en el costado meridional del presbiterio, y fue levantada en el primer tercio del siglo XVII. Muestra exteriormente, en la fachada que da a la Plaza de España, dos blasones de la familia titular, los condes, luego duques, de la Roca, realizados en mármol blanco (Andrés Ordax, 1985: 9-11).

\section{4. \\ Contenido del Apospasmation de rebus emeritensibus}

Centrémonos en el análisis del contenido del Apospasmation. Sus pocas páginas son la constatación clara de un síntoma: la vocación universal de la cultura hispana de finales del siglo XVI y del 
primer tercio del siglo XVII. Mediante este trabajo su autor evidencia la necesidad histórica de recuperación del pasado mítico de Mérida para "ofrecer" a la cultura religiosa de su época un documento hagiográfico erudito. Más allá de las fuentes clásicas recopiladas por Tamayo -todas ellas ya conocidas, y tratadas en más profundidad por otros autores ${ }^{4}$, la importancia de la obra reside en cómo la antigüedad romana de Mérida se ha convertido en un "argumento" corográfico destinado a contextualizar la vida de los mártires cristianos emeritenses. El hecho de que la obra estuviese dedicada al Fray Fernando de Vera, obispo de Cuzco, nos ha permitido trazar una serie de redes familiares y de clientelares que nos permiten afirmar que Tamayo de Vargas estuvo en estrecha relación con el linaje de los Vera de Mérida, especialmente con el Conde de la Roca.

El primer dato que debe ser reseñado es su lugar de impresión: la imprenta de Johannes Meursius en Amberes (1579-1639), anticuario nacido en Loosduinen. Fue autor de ediciones clásicas y tratados, muchos de los cuales fueron impresos en el Thesaurus antiquitatum graecarum de Johann Friedrich Gronovius (1611-1671). Desde finales del siglo XVI e inicios del siglo XVII una gran cantidad de obras españolas científico-técnicas fueron traducidas a otras lenguas (Ramírez Alvarado, 2009: 155; Sánchez Martín, 2010: 115). Amberes durante los siglos XVI y XVII se convertirá en la plaza con mayor

4 Tamayo es heredero de una tradición hispana de recuperación del pasado romano de Mérida que se puede localizar desde la cultura árabe (Ahmad Ibn Muhammad Ibn Musa Al-Razi, 889955 d. C), y el Humanismo y el Renacimiento en las figuras de Pedro del Corral (1430), León de Rosmithal de Blatna (1465-1467), Diego de Sagredo (1526), Gaspar Barreiros (1561), Anton Van den Wyngaerde (1567) o Miguel de Luna (1592). En un contexto temporal más cercano a Tamayo los principales antecedentes de su visión hagiográfica y corográfica fueron Fray Francisco de Coria (1608), la Historia General de España. Antigüedades de España (1616) y Bernabé Moreno de Vargas (1633). Con posterioridad otros autores siguieron escribiendo la Historia de Mérida desde el mismo punto de vista: Ivan Gómez Bravo (1638), Conde de Koenigsmark (1659) o William Bromley (1693-1695). 
actividad impresora a escala europea y, por tanto, uno de los más importantes centros comerciales del libro español.

Dentro de la corriente hagiográfica anteriormente descrita -y en el contexto físico de Mérida y temporal de Tamayo en el primer tercio del siglo XVII- se reeditó las Vitas Sanctorum Patrum Emeretensium, un opúsculo anónimo del siglo VII. En la versión de Tamayo se incluye el Apospasmation (Morán Sánchez, 2009: 76-79). Tamayo hace en este apéndice un análisis de las antigüedades emeritenses y de la historia de la ciudad a través de las fuentes clásicas, pero también basándose en otros trabajos anteriores, como el de Miguel de Luna, Pedro de Medina y, aunque no lo menciona, puede que también el de Moreno de Vargas 5 . La enumeración de las ruinas y su análisis sirven como marco contextual de los mártires y del desarrollo de la primitiva iglesia cristiana, verdadero objetivo de la obra. Acaba este apéndice haciendo una relación de los obispos y de la historia eclesiástica de Mérida, así como de sus mártires y santos.

En este sentido, Tamayo es heredero de una tradición histórica que ya desde hacía varias generaciones venía recuperando la imagen romana de Mérida. Para tal propósito, recoge Tamayo la comparación de Mérida con Roma que ya se ha visto en otros autores, tales como altera Roma, identificación que se repetirá posteriormente. Como muestra de esta nueva forma de abordar la historia surgida en el siglo XVI, Tamayo se basa en testimonios numismáticos y epigráficos para demostrar los orígenes romanos de la ciudad. Su interés se centra en dejar clara la fundación romana de la ciudad y el relato posterior de su historia con la conquista goda y árabe.

En primer lugar narra la fundación augustea de la ciudad con los soldados eméritos ("emeriti") de la guerra cántabra en el 23 a. C., a los que concedió una gran cantidad de tierra y la posibilidad de que fundaran una ciudad, citando el relato de Dion Casio. Así se fundó la "muy ilustre y valerosa" Augusta Emerita, que toma el nombre de los soldados y de Augusto. Se refiere también a otras fuentes clásicas, como Plinio el Viejo, Estrabón y Ptolomeo, y a obras ante-

5 La edición, traducción y análisis en profundidad de la obra será realizada en trabajos posteriores debido a la limitación de espacio de la presente publicación. 
riores como la de Miguel de Luna y las fundaciones legendarias de la ciudad, a las que no concede mucho crédito. Tamayo cita a Dion Casio como fuente primordial para muchos de los datos aportados, y también recoge un testimonio numismático donde aparecería el nombre de Mérida junto al de Publio Carisio, que habría sido el encargado de la edificación de la ciudad. En su enumeración de edificios romanos cuenta Mérida con ejemplos de arquitectura pública ad Roma imitationem: teatro, arco triunfal o de trofeo, naumachia y Ponte Romanis operis longissimo. También incluye las rutas del Itinerario de Antonino (siglo III) como referente de las amplias rutas comerciales y de comunicación de la ciudad. Describe la situación geográfica de la ciudad y analiza su territorio según las fuentes antiguas, basándose también en distintos epígrafes para establecer las vías de comunicación que partían de la ciudad y los lugares hacia los que se dirigían. Incluye el poema de Prudencio sobre las magnificencias de Mérida y la cita de Isidoro de Sevilla.

Tras hablar del río Guadiana, prosigue su relato sobre los restos arqueológicos de la ciudad que dice tomar de "nuestros" escritores, no de los "árabes" y da las medidas de las murallas, las numerosas torres y las puertas de la ciudad (Morán Sánchez 2009, 80); datos que debe tomar de Pedro de Medina a juzgar por el número de puertas (cuarenta y cuatro). Se hace eco del poema que ya incluía Moreno de Vargas en la Historia de la Ciudad de Mérida para ilustrar la grandeza de la ciudad: "Mérida que en las Españas / otro tiempo fuiste Roma", y hace alusión a que el pueblo denomina altera Roma, lo que va a constituir una comparativa bastante frecuente en las visiones de los restos arqueológicos posteriores (Sánchez Salor, 1994-95: 63-66).

\section{5. \\ Conclusión}

El testimonio literario de Tomás Tamayo de Vargas en las pocas páginas del Apospasmation supone a la vez un síntoma y una consecuencia de la cosmovisión de la Historia y de la recuperación del 
pasado clásico que se estaba llevando a cabo en el siglo XVII. Por una parte es un síntoma de toda la preocupación arqueológica y erudita que durante los siglos siguientes (especialmente el siglo XVIII) serán temas capitales en el interés revitalizante de la antigüedad clásica en España. Por otra parte es la consecuencia de varias corrientes intelectuales de su época: la hagiografía y la corografía como herramientas utilizadas por los historiadores cercanos al poder para fortalecer sus propias redes clientelares en determinadas zonas de España, como resulta ser Mérida en nuestro caso particular. De ambas tendencias el Apospasmation está reflejando uno de los ejemplos más clarividentes de cómo la recuperación del pasado romano supuso un telón de fondo ideal para la defensa de la fe cristiana. En el futuro esperamos que la traducción y el análisis más detallado de esta obra sigan presentando nuevas hipótesis de trabajo que nos ayuden a completar este complejo puzzle histórico, cultural y artístico del primer tercio del siglo XVII.

\section{Bibliografía}

Alemán Illán, J. (1997): “Una traducción inédita del Ars Poética de Horacio, por Tomás Tamayo de Vargas”. Criticón 70: 117-148.

Álvarez Sáenz de Buruaga, J. M. (1949): “Las ruinas de Emérita y de Itálica a través de Nebrija y Rodrigo Caro". Revista de Estudios Extremeños 3-4: 564-579.

Álvarez Sáenz de Buruaga, J. M. (1976): “Los primeros templos cristianos de Mérida”. Revista de Estudios Extremeños XXXII (I): 141-143.

Álvarez Sáenz de Buruaga, J. M. (1994): Materiales para la Historia de Mérida (de 1637 a 1936). Mérida: Diputación Provincial de Badajoz.

Andrés Ordax, S. (1985): “La iglesia de Santa María la Mayor de Mérida, a fines de la Edad Media". Norba. Revista de Arte 6: 7-28.

Cerrillo Martín de Cáceres, E. (2009): “La invención de la Antigüedad. El caso de Extremadura durante los siglos XVI y XVII". En: J. G. Gorges et al. (eds.), VI Table Ronde sur la Lusitanie Romaine. Lusitania: mito e realidade. Cascais: Câmara Municipal de Cascais, 25-51.

Coello de la Rosa, A., Numhauser, P. (2012): “Introducción: Criollismo y mestizaje en el mundo andino (siglos XVI-XIX)”. Illes i imperis 14: 13-48. 
Cuesta Domingo, M. (2007): “Los Cronistas oficiales de Indias. De López de Velasco a Céspedes del Castillo". Revista Complutense de Historia de América 33: 115-150.

García Hernán, E. (2006): “La España de los Cronistas Reales en los siglos XVI y XVII”. Norba. Revista de Historia 19: 125-150.

García Murga Alcántara, J. (2001): "Noticias de las antigüedades romanas emeritenses a través de viajeros de los siglos XVI a XIX”. Coloquios Históricos de Extremadura 28: 187-192.

Ginarte González, V. (1989): "Instrucciones al Conde de la Roca para la embajada extraordinaria en Saboya y ordinaria en Venecia". Hispania: Revista española de historia 49 (172): 733-752.

González Hernández, Ma C. (2012):. La "Junta de libros" de Tamayo de Vargas: ensayo de documentación bibliográfica. Tesis Doctoral presentada en la Universidad Complutense de Madrid, http://eprints.ucm.es/17024/ [23.12.2017].

Kagan, R. (1995): “La corografía en la Castilla moderna: género, historia, nación”. Studia Historica. Historia moderna XIII: 47-59.

Kagan, R. (2010): Los cronistas y la Corona. La política de la Historia de España en las Edades Media y Moderna. Madrid: Marcial Pons.

Lozano Bartolozzi, M. (1997): "Los conventos de Mérida en la historia moderna. Fundaciones, supervivencia, transformación, ruina o reutilización". Norba-arte XVII: 121-148.

Marías, F. (2012): Pinturas de historia, imágenes políticas. Repensando el salón de reinos. Discurso leído el día 24 de junio de 2012 en el acto de su recepción por el Excmo. Sr. D. Fernando Marías y contestación por la Excma. Sra. Da Carmen Sanz Ayán. Madrid.

Morán Sánchez, C. (2009): Piedras, Ruinas, Antiguallas. Visiones de los restos arqueológicos de Mérida Siglos XVI a XIX. Mérida: Dirección General de Patrimonio Cultural.

Moreno de Vargas, B. (1992): Historia de la ciudad de Mérida (Madrid, 1633). Badajoz: Patronato de la Biblioteca Municipal y Casa de Cultura de Mérida. Navarro del Castillo, V. (1963): "Bernabé Moreno de Vargas, historiador de Mérida (Apuntes biográficos)". Revista de Estudios Extremeños XIX (III): 605-626.

Ramírez Alvarado, M. (2009): “Información y contrainformación: la evolución de la imprenta en el período de la Reforma luterana y de la Contrarreforma”. Anàlisi 39: 149-162. 
Rodríguez Grajera, A. (1985): La población de Mérida en el siglo XVII. Badajoz: Ed. Diputación de Badajoz.

Ruiz Pérez, P. (2007): “La Junta de libros de Tamayo: bibliografía, parnaso y poetas". Bulletin Hispanique 109 (2): 511-543.

Sánchez Martín, F. J. (2010): "La contribución de las prensas de Amberes a la literatura científica renacentista”. Cuadernos del Instituto Historia de la Lengua 4: 105-127.

Sánchez Salor, E. (1994-1995): “La 'Historia de la ciudad de Mérida' de Bernabé Moreno de Vargas”. Anas 7-8: 57-77.

Sierra Matute, V. (2009): “Tomás Tamayo de Vargas y las 'Cartas al cronista Andrés de Uztarroz' ". Voz y letra XX (2): 137-161.

Tejada Vizuete, F. (1998-1999): "Recorrido histórico-artístico por la iglesia de Santa Eulalia de Mérida (siglos XV-XVIII)". Norba-arte XVIII-XIX: 125-159.

Túrrez, I. (2008): "Ideas acerca de la lengua de Tomás Tamayo de Vargas: una lectura de sus anotaciones a Garcilaso". ASJU Geh 51: 793-804.

Vives Castell, J. (1949). “La dedicación de la iglesia de Santa María, de Mérida”. Analecta sacra tarraconensia 22: 67. 